\title{
KONTROL OPTIMAL MODEL PENYEBARAN VIRUS KOMPUTER DENGAN PENGARUH KOMPUTER EKSTERNAL YANG TERINFEKSI \\ DAN REMOVABLE STORAGE MEDIA
}

\author{
Dewi Erla Mahmudah \\ STMIK Widya Utama \\ mdewierla@gmail.com \\ Muhammad Zidny Naf'an \\ ST3 Telkom Purwokerto \\ zidny@st3telkom.ac.id \\ Muh Sofi'i \\ STMIK Widya Utama \\ sof.swu@gmail.com \\ Wika Purbasari \\ STMIK Widya Utama \\ wika@wikapurbasari.net
}

\begin{abstract}
In this paper, we discuss an optimal control on the spread of computer viruses under the effects of infected external computers and removable storage media. Prevention Strategies do with ascertaining control prevention to minimize the number of infective computers (Latent and Breakingout) and installing effective antivirus programs in each sub-population. The aim are to derive optimal prevention strategies and minimize the cost associated with the control. The characterization of optimal control is perform analitically by applying Pontryagin Minimum Principle. The obtained optimality system of Hamilton fuction is satistfy the optimality condition.
\end{abstract}

Keywords: computer virus, removable storage media, pontryagin minimum principle, Hamilton function.

\begin{abstract}
ABSTRAK. Pada penelitian ini dibahas kontrol optimal model penyebaran virus komputer dengan pengaruh komputer eksternal yang terinfeksi dan removable storage media. Strategi pencegahan dilakukan dengan menentukan kontrol pencegahan untuk meminimumkan jumlah komputer yang terinfeksi (Laten dan Breakingout) dan pemasangan program antivirus pada setiap sub-populasi. Tujuan kontrol optimal adalah untuk mendapatkan strategi pencegahan optimal dan meminimumkan biaya yang digunakan untuk menerapkan kontrol. Kontrol optimal diperoleh dengan menerapkan Prinsip Minimum Pontryagin. Solusi optimal pada fungsi Hamilton yang dibentuk memenuhi kondisi optimal.
\end{abstract}

Kata Kunci: virus komputer, removable storage media, prinsip minimum pontryagin, fungsi Hamilton. 


\section{PENDAHULUAN}

Virus komputer merupakan ancaman besar pada jaringan komputer. Sama halnya seperti virus biologi, virus komputer bekerja dengan cara menggandakan dirinya sendiri dan menyebar dengan cara menyisipkan dirinya ke sel makhluk hidup. Penggunaan sistem jaringan komputer, menyebabkan virus komputer dapat menyebar dari komputer satu ke komputer lainnya yang saling terhubung. Komputer yang sudah terjangkit virus tidak dapat bekerja secara optimum karena semakin lama virus tersebut dapat menyebabkan kerusakan pada software maupun hardware komputer. Oleh karena itu, perlu adanya pengontrolan penyebaran virus komputer pada jaringan komputer (Achadiyah, 2015).

Chen dkk (2015) membuat strategi kontrol pencegahan berupa pemasangan antivirus pada komputer dengan kategori breakout untuk meminimalkan jumlah komputer breakout dan biaya yang digunakan dalam menerapkan kontrol. Namun, pada hasil simulasi numerik menunjukkan bahwa komputer dengan kategori breakout masih eksis dan jumlah komputer laten bertambah.

Darajat dkk (2016) membuat strategi yang berbeda, yaitu meminimalkan jumlah komputer laten dan breakout serta biaya pemasangan antivirus pada setiap sub populasi. Dengan menerapkan strategi ini, pemasangan antivirus pada komputer dengan kategori susceptible $(S)$ sangat berpengaruh dalam menekan penyebaran virus komputer.

Berbeda dengan penelitian di atas yang meneliti tentang model SLBS, Yang dkk (2012) mengenalkan model penyebaran virus komputer dengan empat kompartemen, yaitu model SLBRS. Kemudian, Yang dkk (2014) mengembangkan model dengan mempertimbangkan efek komputer terinfeksi yang terhubung dengan internet. Namun, model ini tidak mengembangkan dampak removable storage media pada perpindahan virus.

Zhang (2016) mengenalkan model baru yaitu model penyebaran virus komputer dengan pengaruh komputer eksternal yang terinfeksi dan removable storage media yang dikategorikan menjadi empat sub populasi: komputer 
susceptible $(S \equiv S(t))$, komputer latent $(L \equiv L(t))$, komputer breakout $(B \equiv$ $B(t))$, dan komputer removed $(R \equiv R(t))$. Diagram kompartemen dari model ini adalah sebagai berikut:

$$
\begin{aligned}
& \frac{d S}{d t}=b_{1}+\gamma_{2} L+\gamma_{3} B+\eta R-\mu S-\gamma_{1} S-\beta_{1} L S-\beta_{2} B S-\theta S \\
& \frac{d L}{d t}=b_{2}+\beta_{1} L S+\beta_{2} B S+\theta S-\gamma_{1} L-\gamma_{2} L-\mu L-\alpha L \\
& \frac{d B}{d t}=b_{3}+\alpha L-\mu B-\gamma_{1} B-\gamma_{3} B \\
& \frac{d R}{d t}=b_{4}+\gamma_{1} S+\gamma_{1} L+\gamma_{1} B-\eta R-\mu R
\end{aligned}
$$

dimana tingkat kematian (komputer tidak dapat digunakan kembali) dari setiap kompartemen adalah konstan positif $\mu$.Tingkat pertumbuhan dari keempat kompartemen masing-masing adalah konstan positif $b_{1}, b_{2}, b_{3}$ dan $b_{4}$. Setiap komputer pada kompartemen susceptible $(S)$ terinfeksi dari komputer latent $(L)$ atau breakout $(B)$ dengan probabilitas berturut-turut adalah $\beta_{1} L$ atau $\beta_{2} B$, dengan $\beta_{1}$ dan $\beta_{2}$ adalah konstan positif. Setiap komputer pada kompartemen susceptible $(S)$ terinfeksi dari removable storage media yang terinfeksi, dengan probabilitas $\theta$. Setiap komputer pada kompartemen latent $(L)$ menjadi breakout $(B)$ dengan probabilitas $\alpha$. Setiap komputer pada kompartemen removed $(R)$ kehilangan imunitas dengan probabilitas $\eta$. Karena pemasangan dan pemutakhiran software antivirus tepat waktu, setiap komputer yang tersambung internet menjadi pulih dengan probabilitas $\gamma_{1}$. Dan yang terakhir, karena pemasangan ulang sistem operasi, setiap komputer latent $(L)$ atau breakout $(B)$ menjadi susceptible $(S)$ dengan probabilitas $\gamma_{2}$ atau $\gamma_{3}$. Model penyebaran virus komputer dengan pengaruh komputer eksternal yang terinfeksi dan removable storage media dapat dilihat pada Gambar. 


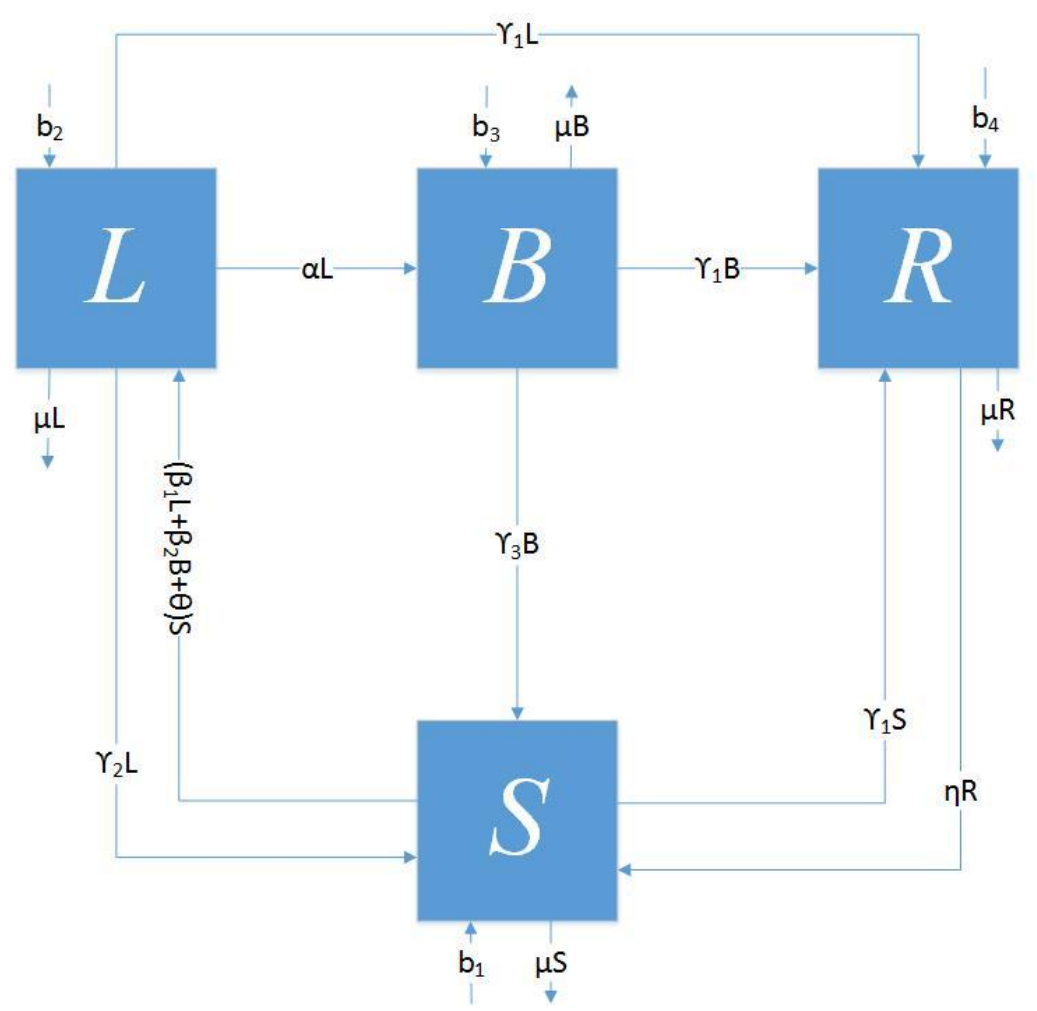

Gambar. Diagram Kompartemen Model Penyebaran Virus Komputer Dengan Pengaruh Komputer Eksternal yang Terinfeksi dan Removable Storage Media

\section{METODE PENELITIAN}

Langkah-langkah dalam penelitian ini adalah:

1. Mengkonstruksi model penyebaran virus komputer dengan pengaruh komputer eksternal yang terinfeksi dan removable storage media (Zhang, 2016).

2. Mengkonstruksi model penyebaran virus komputer dengan pengaruh komputer eksternal yang terinfeksi dan removable storage media dengan kontrol.

3. Menentukan kontrol optimal.

Penyelesaian kontrol optimal dengan menggunakan Prinsip Minimum Pontryagin sebagai berikut:

a. Membentuk fungsi Hamilton

$$
H(t, \mathbf{x}(t), \mathbf{u}(t), \lambda(t))=f(t, \mathbf{x}(t), \mathbf{u}(t))+\lambda(t) \mathbf{g}(t, \mathbf{x}(t), \mathbf{u}(t)) .
$$


b. Menyelesaikan $\frac{\partial H(t, \mathbf{x}(t), \mathbf{u}(t), \lambda(t))}{\partial \mathbf{u}}=0$ untuk mendapatkan $\mathbf{u}^{*}=$ $\mathbf{u}^{*}(t, \mathbf{x}(t), \lambda(t))$.

c. Mengamati $H^{*}(t, \mathbf{x}(t), \lambda(t))=H\left(t, \mathbf{x}(t), \mathbf{u}^{*}(t, \mathbf{x}(t), \lambda(t)), \lambda(t)\right)=$ $\min _{\mathbf{u} \in U} H(t, \mathbf{x}(t), \mathbf{u}(t), \lambda(t))$.

d. Menyelesaikan persamaan state $\dot{\mathbf{x}}(t)=\frac{\partial H(t, \mathbf{x}(t), \mathbf{u}(t), \lambda(t))}{\partial \lambda}$ dan persamaan costate $\quad \dot{\lambda}(t)=-\frac{\partial H(t, \mathbf{x}(t), \mathbf{u}(t), \lambda(t))}{\partial \mathbf{x}} \quad$ dengan kondisi transversal $\lambda(t)=0$.

e. Mensubstitusikan hasil dari langkah d. ke $\mathbf{u}^{*}$ untuk menentukan kontrol optimal.

(Gopal, 1985).

\section{PERMASALAHAN KONTROL OPTIMAL}

\subsection{Konstruksi Model dengan Kontrol}

Pada penelitian ini diterapkan kontrol $u_{1} \equiv u_{1}(t), u_{2} \equiv u_{2}(t), u_{3} \equiv u_{3}(t)$ dan $u_{4} \equiv u_{4}(t)$. Kontrol $u_{1}$ adalah kontrol pencegahan untuk memberi perlindungan pada komputer susceptible $(S)$ ketika berinteraksi dengan komputer yang terinfeksi atau removable storage media. Kontrol $u_{2}$ dan $u_{3}$ adalah kontrol untuk memperbaiki komputer yang terinfeksi (latent $(L)$ dan breakout $(B)$ ). Karena keterbatasan kemampuan antivirus, diasumsikan bahwa dengan menerapkan kontrol $u_{3}$ pada komputer breakout $(B)$ pada waktu $t$ mengakibatkan $\xi u_{3} B$ pada komputer breakout $(B)$ menjadi susceptible $(S)$, dan $(1-\xi) u_{3} B$ pada komputer breakout $(B)$ menjadi latent $(L)$, dengan $\xi \in[0,1]$.

Kontrol $u_{4}$ adalah kontrol pencegahan untuk memberi perlindungan pada komputer recovered $(R)$. Model penyebaran virus komputer dengan pengaruh komputer eksternal yang terinfeksi dan removable storage media dengan variabel kontrol, yang merupakan pengembangan dari persamaan (1.1-1.4) adalah sebagai berikut: 


$$
\begin{aligned}
& \frac{d S}{d t}=b_{1}+\gamma_{2} L+\gamma_{3} B+\eta R-\mu S-\gamma_{1} S \\
& -\left(1-u_{1}\right)\left(\beta_{1} L S+\beta_{2} B S+\theta S\right)+u_{2} L+\xi u_{3} B+u_{4} R \\
& \frac{d L}{d t}=b_{2}+\left(1-u_{1}\right)\left(\beta_{1} L S+\beta_{2} B S+\theta S\right)-\gamma_{1} L-\gamma_{2} L-\mu L-\alpha L \\
& -u_{2} L+(1-\xi) u_{3} B \\
& \frac{d B}{d t}=b_{3}+\alpha L-\mu B-\gamma_{1} B-\gamma_{3} B-u_{3} B \\
& \frac{d R}{d t}=b_{4}+\gamma_{1} S+\gamma_{1} L+\gamma_{1} B-\eta R-\mu R-u_{4} R
\end{aligned}
$$

dimana $b_{1}, b_{2}, b_{3}, b_{4}, \gamma_{1}, \gamma_{2}, \gamma_{3}, \eta, \mu, \xi, \beta_{1}, \beta_{2}, \theta, \alpha$, adalah konstan positif.

\subsection{Penyelesaian Kontrol Optimal}

Penyelesaian kontrol optimal disini bertujuan untuk meminimumkan subpopulasi komputer latent $(L)$ dan breakout $(B)$ dan biaya yang digunakan untuk menerapkan kontrol $u_{1} \equiv u_{1}(t), u_{2} \equiv u_{2}(t), u_{3} \equiv u_{3}(t)$ dan $u_{4} \equiv u_{4}(t)$ yaitu dengan meminimumkan fungsi objektif berikut:

$$
J\left(u_{1}, u_{2}, u_{3}, u_{4}\right)=\int_{0}^{T}\left(m L+n B+w u_{1}^{2}+x u_{2}^{2}+y u_{3}^{2}+z u_{4}^{2}\right) d t
$$

dengan kendala sistem persamaan $(2.1-2.4)$, dengan $m, n, w, x, y$ dan $z$ adalah bobot yang dikenakan pada sistem dengan $t \in[0, T]$.

Kemudian akan ditentukan kontrol optimal $\bar{u}_{1}, \bar{u}_{2}, \bar{u}_{3}$ dan $\bar{u}_{4}$ sehingga berlaku

$$
J\left(\bar{u}_{1}, \bar{u}_{2}, \bar{u}_{3}, \bar{u}_{4}\right)=\min \left\{J\left(u_{1}, u_{2}, u_{3}, u_{4}\right) \mid u_{1}, u_{2}, u_{3}, u_{4} \in U\right\},
$$

dimana $U=\left\{\left(u_{1}, u_{2}, u_{3}, u_{4}\right): 0 \leq u_{1} \leq 1,0 \leq u_{2} \leq 1,0 \leq u_{3} \leq 1,0 \leq u_{4} \leq 1\right\}$.

Masalah kontrol optimal diselesaikan dengan memenuhi kondisi-kondisi pada Prinsip Minimum Pontryagin. Terlebih dahulu didefinisikan fungsi Hamilton sebagai berikut: 


$$
\begin{aligned}
H=m L+n B & +w u_{1}^{2}+x u_{2}^{2}+y u_{3}^{2}+z u_{4}^{2} \\
& +\lambda_{S}\left(b_{1}+\gamma_{2} L+\gamma_{3} B+\eta R-\mu S-\gamma_{1} S\right. \\
& \left.-\left(1-u_{1}\right)\left(\beta_{1} L S+\beta_{2} B S+\theta S\right)+u_{2} L+\xi u_{3} B+u_{4} R\right) \\
& +\lambda_{L}\left(b_{2}+\left(1-u_{1}\right)\left(\beta_{1} L S+\beta_{2} B S+\theta S\right)-\gamma_{1} L-\gamma_{2} L-\mu L-\alpha L\right. \\
& \left.-u_{2} L+(1-\xi) u_{3} B\right)+\lambda_{B}\left(b_{3}+\alpha L-\mu B-\gamma_{1} B-\gamma_{3} B-u_{3} B\right) \\
& +\lambda_{R}\left(b_{4}+\gamma_{1} S+\gamma_{1} L+\gamma_{1} B-\eta R-\mu R-u_{4} R\right)
\end{aligned}
$$

dimana $\lambda_{S} \equiv \lambda_{S}(t), \lambda_{L} \equiv \lambda_{L}(t), \lambda_{B} \equiv \lambda_{B}(t)$ dan $\lambda_{R} \equiv \lambda_{R}(t)$ adalah variabel costate.

Menurut Prinsip Minimum Pontryagin, fungsi Hamilton mencapai solusi optimal jika memenuhi kondisi-kondisi berikut.

1. Kondisi Stasioner

a. $\frac{\partial H}{\partial u_{1}}=0 \Leftrightarrow 2 w u_{1}+\lambda_{S}\left(\beta_{1} L S+\beta_{2} B S+\theta S\right)-\lambda_{L}\left(\beta_{1} L S+\beta_{2} B S+\theta S\right)=$

0

$$
\Leftrightarrow \tilde{u}_{1}=\frac{\left(\lambda_{L}-\lambda_{S}\right)\left(\beta_{1} L S+\beta_{2} B S+\theta S\right)}{2 w}
$$

Karena didefinisikan $0 \leq u_{1} \leq 1$, solusi $\bar{u}_{1}$ adalah

$$
\bar{u}_{1}=\left\{\begin{array}{cc}
0, & \tilde{u}_{1} \leq 0 \\
\tilde{u}_{1}, & 0 \leq \tilde{u}_{1} \leq 1 \\
1, & \tilde{u}_{1} \geq 1
\end{array}\right.
$$

sehingga kontrol optimal $\bar{u}_{1}$ dapat dinyatakan sebagai

$$
\bar{u}_{1}=\min \left\{\max \left(0, \frac{\left(\lambda_{L}-\lambda_{S}\right)\left(\beta_{1} L S+\beta_{2} B S+\theta S\right)}{2 w}\right), 1\right\} .
$$

b. $\frac{\partial H}{\partial u_{2}}=0 \Leftrightarrow 2 x u_{2}+\lambda_{S} L-\lambda_{L} L=0$

$$
\Leftrightarrow \tilde{u}_{2}=\frac{\left(\lambda_{L}-\lambda_{S}\right) L}{2 x}
$$

Karena didefinisikan $0 \leq u_{2} \leq 1$, solusi $\bar{u}_{2}$ adalah

$$
\bar{u}_{2}=\left\{\begin{array}{cc}
0, & \tilde{u}_{2} \leq 0 \\
\tilde{u}_{2}, & 0 \leq \tilde{u}_{2} \leq 1 \\
1, & \tilde{u}_{2} \geq 1
\end{array}\right.
$$

sehingga kontrol optimal $\bar{u}_{2}$ dapat dinyatakan sebagai

$$
\bar{u}_{2}=\min \left\{\max \left(0, \frac{\left(\lambda_{L}-\lambda_{S}\right) L}{2 x}\right), 1\right\} .
$$


c. $\frac{\partial H}{\partial u_{3}}=0 \Leftrightarrow 2 y u_{3}+\lambda_{S} \xi B+\lambda_{L}(1-\xi) B-\lambda_{B} B=0$

$$
\Leftrightarrow \tilde{u}_{3}=\frac{\lambda_{B} B-\lambda_{L}(1-\xi) B-\lambda_{S} \xi B}{2 y}
$$

Karena didefinisikan $0 \leq u_{3} \leq 1$, solusi $\bar{u}_{3}$ adalah

$$
\bar{u}_{3}=\left\{\begin{array}{cc}
0, & \tilde{u}_{3} \leq 0 \\
\tilde{u}_{3}, & 0 \leq \tilde{u}_{3} \leq 1 \\
1, & \tilde{u}_{3} \geq 1
\end{array}\right.
$$

sehingga kontrol optimal $\bar{u}_{3}$ dapat dinyatakan sebagai

$$
\bar{u}_{3}=\min \left\{\max \left(0, \frac{\lambda_{B} B-\lambda_{L}(1-\xi) B-\lambda_{S} \xi B}{2 y}\right), 1\right\} .
$$

d. $\frac{\partial H}{\partial u_{4}}=0 \Leftrightarrow 2 z u_{4}+\lambda_{S} R-\lambda_{R} R=0$

$$
\Leftrightarrow \tilde{u}_{4}=\frac{\left(\lambda_{R}-\lambda_{S}\right) R}{2 z}
$$

Karena didefinisikan $0 \leq u_{4} \leq 1$, solusi $\bar{u}_{4}$ adalah

$$
\bar{u}_{4}=\left\{\begin{array}{cc}
0, & \tilde{u}_{4} \leq 0 \\
\tilde{u}_{4}, & 0 \leq \tilde{u}_{4} \leq 1 \\
1, & \tilde{u}_{4} \geq 1
\end{array}\right.
$$

sehingga kontrol optimal $\bar{u}_{4}$ dapat dinyatakan sebagai

$$
\bar{u}_{4}=\min \left\{\max \left(0, \frac{\left(\lambda_{R}-\lambda_{S}\right) R}{2 z}\right), 1\right\} \text {. }
$$

2. Persamaan state

$$
\begin{aligned}
& \frac{d H}{d \lambda_{S}}=\frac{d S}{d t}=b_{1}+\gamma_{2} L+\gamma_{3} B+\eta R-\mu S-\gamma_{1} S-\left(1-u_{1}\right)\left(\beta_{1} L S+\beta_{2} B S+\theta S\right) \\
& +u_{2} L+\xi u_{3} B+u_{4} R \\
& \frac{d H}{d \lambda_{L}}=\frac{d L}{d t}=b_{2}+\left(1-u_{1}\right)\left(\beta_{1} L S+\beta_{2} B S+\theta S\right)-\gamma_{1} L-\gamma_{2} L-\mu L-\alpha L-u_{2} L \\
& +(1-\xi) u_{3} B \\
& \frac{d H}{d \lambda_{B}}=\frac{d B}{d t}=b_{3}+\alpha L-\mu B-\gamma_{1} B-\gamma_{3} B-u_{3} B \\
& \frac{d H}{d \lambda_{R}}=\frac{d R}{d t}=b_{4}+\gamma_{1} S+\gamma_{1} L+\gamma_{1} B-\eta R-\mu R-u_{4} R
\end{aligned}
$$

dengan kondisi awal $S(0)=S_{0}, L(0)=L_{0}, B(0)=B_{0}$ dan $R(0)=R_{0}$. 
3. Persamaan costate

$$
\begin{aligned}
& \frac{d \lambda_{S}}{d t}=-\frac{d H}{d S}=-\left(\left(-\mu-\gamma_{1}-\left(1-u_{1}\right)\left(\beta_{1} L+\beta_{2} B+\theta\right)\right) \lambda_{S}+((1-\right. \\
& \left.\left.\left.u_{1}\right)\left(\beta_{1} L+\beta_{2} B+\theta\right)\right) \lambda_{L}+\gamma_{1} \lambda_{R}\right) \\
& \frac{d \lambda_{L}}{d t}=-\frac{d H}{d L}=-\left(c+\left(\gamma_{2}-\beta_{1} S+u_{1} \beta_{1} S+u_{2}\right) \lambda_{S}+\left(\beta_{1} S-u_{1} \beta_{1} S-\gamma_{1}-\right.\right. \\
& \left.\left.\gamma_{2}-\mu-\alpha-u_{2}\right) \lambda_{L}+\alpha \lambda_{B}+\gamma_{1} \lambda_{R}\right) \\
& \frac{d \lambda_{B}}{d t}=-\frac{d H}{d B}=-\left(d+\left(\gamma_{3}-\beta_{2} S+u_{1} \beta_{2} S+\xi u_{3}\right) \lambda_{S}+\left(\beta_{2} S-u_{1} \beta_{2} S+u_{3}-\right.\right. \\
& \left.\left.\xi u_{3}\right) \lambda_{L}+\left(-\mu-\gamma_{1}-\gamma_{3}-u_{3}\right) \lambda_{B}+\gamma_{1} \lambda_{R}\right) \\
& \frac{d \lambda_{R}}{d t}=-\frac{d H}{d R}=-\left(\left(\eta+u_{4}\right) \lambda_{S}+\left(-\eta-\mu-u_{4}\right) \lambda_{R}\right)
\end{aligned}
$$

dengan kondisi transversal $\lambda_{S}(T)=\lambda_{L}(T)=\lambda_{B}(T)=\lambda_{R}(T)=0$.

Sistem optimal diperoleh dengan memasukkan kontrol optimal $\overline{\mathbf{u}}$ ke sistem persamaan state dan costate sehingga diperoleh sistem yang optimal sebagai berikut:

$$
\begin{gathered}
\frac{d S^{*}}{d t}=f_{1}\left(S^{*}, L^{*}, B^{*}, R^{*}, \bar{u}_{1}, \bar{u}_{2}, \bar{u}_{3}, \bar{u}_{4}\right) \\
\frac{d L^{*}}{d t}=f_{2}\left(S^{*}, L^{*}, B^{*}, R^{*}, \bar{u}_{1}, \bar{u}_{2}, \bar{u}_{3}, \bar{u}_{4}\right) \\
\frac{d B^{*}}{d t}=f_{3}\left(S^{*}, L^{*}, B^{*}, R^{*}, \bar{u}_{1}, \bar{u}_{2}, \bar{u}_{3}, \bar{u}_{4}\right) \\
\frac{d R^{*}}{d t}=f_{3}\left(S^{*}, L^{*}, B^{*}, R^{*}, \bar{u}_{1}, \bar{u}_{2}, \bar{u}_{3}, \bar{u}_{4}\right) \\
\frac{d \lambda_{S}{ }^{*}}{d t}=-\left(\left(-\mu-\gamma_{1}-\left(1-\bar{u}_{1}\right)\left(\beta_{1} L^{*}+\beta_{2} B^{*}+\theta\right)\right) \lambda_{S}{ }^{*}\right. \\
\left.+\left(\left(1-\bar{u}_{1}\right)\left(\beta_{1} L^{*}+\beta_{2} B^{*}+\theta\right)\right) \lambda_{L}{ }^{*}+\gamma_{1} \lambda_{R}{ }^{*}\right) \\
\frac{d \lambda_{L}{ }^{*}}{d t}=-\left(c+\left(\gamma_{2}-\beta_{1} S^{*}+\bar{u}_{1} \beta_{1} S^{*}+\bar{u}_{2}\right) \lambda_{S}{ }^{*}\right. \\
+\left(\beta_{1} S^{*}-\bar{u}_{1} \beta_{1} S^{*}-\gamma_{1}-\gamma_{2}-\mu-\alpha-\bar{u}_{2}\right) \lambda_{L}{ }^{*}+\alpha \lambda_{B}{ }^{*} \\
\left.+\gamma_{1} \lambda_{R}{ }^{*}\right) \\
\frac{d \lambda_{B}{ }^{*}}{d t}=-(d+ \\
+\left(\gamma_{3}-\beta_{2} S^{*}+\bar{u}_{1} \beta_{2} S^{*}+\xi \bar{u}_{3}\right) \lambda_{S}{ }^{*} \\
+\left(\beta_{2} S^{*}-\bar{u}_{1} \beta_{2} S^{*}+\bar{u}_{3}-\xi \bar{u}_{3}\right) \lambda_{L}{ }^{*} \\
\left.+\left(-\mu-\gamma_{1}-\gamma_{3}-\bar{u}_{3}\right) \lambda_{B}{ }^{*}+\gamma_{1} \lambda_{R}{ }^{*}\right)
\end{gathered}
$$




$$
\frac{d \lambda_{R}^{*}}{d t}=-\left(\left(\eta+\bar{u}_{4}\right) \lambda_{S}^{*}+\left(-\eta-\mu-\bar{u}_{4}\right) \lambda_{R}{ }^{*}\right)
$$

dengan kondisi batas $S(0)=S_{0}, L(0)=L_{0}, B(0)=B_{0}$ dan $R(0)=R_{0}$, dan $\lambda_{S}(T)=\lambda_{L}(T)=\lambda_{B}(T)=\lambda_{R}(T)=0$.

Berdasarkan uraian di atas, diperoleh teorema berikut.

Teorema 1. Diberikan kontrol optimal $\bar{u}_{1}, \bar{u}_{2}, \bar{u}_{3}, \bar{u}_{4}$, dan solusi state optimal $S^{*}, L^{*}, B^{*}$ dan $R^{*}$ yang meminimumkan fungsi objektif $J\left(u_{1}, u_{2}, u_{3}, u_{4}\right)$ sehingga terdapat variabel costate $\lambda_{S}, \lambda_{L}, \lambda_{B}$ dan $\lambda_{R}$ yang memenuhi

$$
\begin{aligned}
& \frac{d \lambda_{S}}{d t}=-\left(\left(-\mu-\gamma_{1}-\left(1-u_{1}\right)\left(\beta_{1} L+\beta_{2} B+\theta\right)\right) \lambda_{S}\right. \\
& \left.+\left(\left(1-u_{1}\right)\left(\beta_{1} L+\beta_{2} B+\theta\right)\right) \lambda_{L}+\gamma_{1} \lambda_{R}\right) \\
& \begin{aligned}
& \frac{d \lambda_{L}}{d t}=-(m+\left(\gamma_{2}-\beta_{1} S+u_{1} \beta_{1} S+u_{2}\right) \lambda_{S} \\
&\left.+\left(\beta_{1} S-u_{1} \beta_{1} S-\gamma_{1}-\gamma_{2}-\mu-\alpha-u_{2}\right) \lambda_{L}+\alpha \lambda_{B}+\gamma_{1} \lambda_{R}\right) \\
& \frac{d \lambda_{B}}{d t}=-(n+\left(\gamma_{3}-\beta_{2} S+u_{1} \beta_{2} S+\xi u_{3}\right) \lambda_{S}+\left(\beta_{2} S-u_{1} \beta_{2} S+u_{3}-\xi u_{3}\right) \lambda_{L} \\
&\left.+\left(-\mu-\gamma_{1}-\gamma_{3}-u_{3}\right) \lambda_{B}+\gamma_{1} \lambda_{R}\right) \\
& \frac{d \lambda_{R}}{d t}=-\left(\left(\eta+u_{4}\right) \lambda_{S}+\left(-\eta-\mu-u_{4}\right) \lambda_{R}\right)
\end{aligned}
\end{aligned}
$$

dengan kondisi transversal $\lambda_{S}(T)=\lambda_{L}(T)=\lambda_{B}(T)=\lambda_{R}(T)=0$, dan kontrol optimal $\bar{u}_{1}, \bar{u}_{2}, \bar{u}_{3}$, dan $\bar{u}_{4}$ memenuhi kodisi optimal,

$$
\begin{aligned}
& \bar{u}_{1}=\min \left\{\max \left(0, \frac{\left(\lambda_{L}-\lambda_{S}\right)\left(\beta_{1} L S-\beta_{2} B S+\theta S\right)}{2 w}\right), 1\right\} \\
& \bar{u}_{2}=\min \left\{\max \left(0, \frac{\left(\lambda_{L}-\lambda_{S}\right) L}{2 x}\right), 1\right\} \\
& \bar{u}_{3}=\min \left\{\max \left(0, \frac{\lambda_{B} B-\lambda_{L}(1-\xi) B-\lambda_{S} \xi B}{2 y}\right), 1\right\} \\
& \bar{u}_{4}=\min \left\{\max \left(0, \frac{\left(\lambda_{R}-\lambda_{S}\right) R}{2 z}\right), 1\right\} .
\end{aligned}
$$




\section{KESIMPULAN DAN SARAN}

Dengan menggunakan Prinsip Minimum Pontryagin pada model penyebaran virus komputer dengan pengaruh komputer eksternal yang terinfeksi dan removable storage media dengan kontrol, dibentuk fungsi Hamilton yang memenuhi kondisi optimal sehingga diperoleh kontrol optimal $\overline{u_{1}}, \overline{u_{2}}, \overline{u_{3}}$ dan $\overline{u_{4}}$.

Untuk penelitian selanjutnya, dapat dilakukan simulasi secara numerik dengan menggunakan metode Sweep Maju-Mundur yang dikombinasikan dengan metode Runge-Kutta orde 4.

\section{DAFTAR PUSTAKA}

Achadiyah, A. L., Analisis Kestabilan Model Virus Komputer dengan Infeksi Tunda dan Pemulihan Tunda, Skripsi, IPB, 2015.

Chen, L., Hattaf, K., dan Sun, J., Optimal Control of a Delayed SLBS Computer Virus Model, Physica A, 427 (2015), 244-250.

Darajat, P. P., Suryanto, A., dan Widodo, A., Optimal Control On The Spread of SLBS Computer Virus Model, International Journal of Pure and Applied Mathematics, 107(3) (2016), 749-758.

Gopal, M., Modern Control System Theory. Mohinder Singh Sejwal for Wiley Eastern Limited. 1985.

Yang, M., Zhang, Z., Li, Q., dan Zhang G., An SLBRS Model with Vertical Transmission of Computer Virus over the Internet, Yang, X., Mishra, B.K., dan Liu, Y., Discrete Dynamics in Nature and Society (An International Multidiciplinary Research and Review Journal), Hindawi Publishing Corporation, Egypt, 2012, 84-100.

Yang, X., Liu, B., dan Gan, C., Global Stability of an Epidemic Model of Computer Virus, Ding, H., Lizama, C., N'Guerekata, G.M., dan Cuevas, C., Abstract and Applied Analysis (Asymptotic Behavior of Nonlinear Evolution Equations), Hindawi Publishing Corporation, Egypt, 2014, 2428. 
Zhang, X., Modeling the Spread of Computer Viruses under the Effects of Infected External Computers and Removable Storage Media, International Journal of Security and its Applications, 10(3) (2016), 419-428. 